\title{
Post-release movements of captive-born European mink Mustela lutreola
}

\author{
Lauren A. Harrington ${ }^{1, *}$, Madis Põdra ${ }^{2}$, David W. Macdonald ${ }^{1}$, Tiit Maran ${ }^{2,3}$ \\ ${ }^{1}$ Wildlife Conservation Research Unit, Department of Zoology, University of Oxford, The Recanati-Kaplan Centre, \\ Tubney House, Abingdon Road, Tubney, Oxfordshire OX13 5QL, UK \\ ${ }^{2}$ Institute of Veterinary Medicine and Animal Sciences, Estonian University of Life Sciences, Kreutzwaldi 62, 51014 Tartu, \\ Estonia \\ ${ }^{3}$ Species Conservation Lab, Tallinn Zoological Gardens, Paldiski Road 145, Tallinn 13522, Estonia
}

\begin{abstract}
Naïve captive-bred animals often make excessive movements when released into the wild, which may increase vulnerability to predation, take animals into unsuitable habitat and/or increase the probability of conflict with humans. We analysed the post-release movements of captive-bred European mink Mustela lutreola reintroduced to Hiiumaa Island, Estonia. We tested the effect of pre-release enclosure type, sex, generations in captivity, pregnancy and age on post-release movements, investigated the settlement process and explored the relationship between post-release movements and survival. We found no effect of enclosures on post-release movements in the first 2 wk following release (except that individuals from large naturalistic enclosures spent less time close to water than did animals from standard zoo enclosures) but some evidence of a slight effect at 1 mo post-release. Males moved further at $3 \mathrm{~d}$ (but not $2 \mathrm{wk}$ ) postrelease than did females, and juveniles appeared to move further in the first $3 \mathrm{~d}$ post-release than did $1 \mathrm{yr}$ olds. We were unable to detect a relationship between post-release movements and survival. The largest known cause of mortality was predation, but it was not clear why mink were vulnerable to predation, and the locational data presented here were unable to shed light on this issue. Individual variation also made it difficult to define patterns. These are common problems in reintroductions, and we suggest that in future releases of captive-bred animals, more detailed post-release behavioural observations and investigation of personality types might be insightful.
\end{abstract}

KEY WORDS: Individual variation · Island sanctuary - Mustelid · Pre-release enclosures · Pre-conditioning $\cdot$ Reintroduction $\cdot$ Settlement

\section{INTRODUCTION}

When released into the wild, naïve captive-bred animals often make excessive movements in terms of both distance moved and amount of time spent actively moving (e.g. Robertson \& Harris 1995, Biggins et al. 1999, 2011). Excessive activity in open areas renders animals vulnerable to predation (Miller et al. 1994), and extensive movements may take animals into unsuitable habitat (Cook 2004, van Heezik et al. 2009) and/or increase the probability of conflict with humans (McLellan \& Rabon 2006). The rarely tested assumption is that greater movements or dispersal distances have a negative impact on survival (e.g. Moehrenschlager \& Macdonald 2003; see also Biggins et al. 1999). Further, animals that fail to settle and establish home ranges are unlikely to contribute to the restoration of the species.

One method commonly used to prepare captivebred animals for 'life in the wild' is to 'pre-condition' them to their natural environment prior to release while still in captivity (e.g. Biggins et al. 1999, Stoin- 
ski \& Beck 2004; see also Roe et al. 2010), after which they may be released with or without further support in either a 'soft' release (with shelter and/or food) or a 'hard' release (with no support). The theoretical basis for this approach is that experience early in life (but not necessarily during any particular sensitive period) affects future habitat preferences and individual performance, or behaviour, in that habitat (Davis \& Stamps 2004, Stamps \& Swaisgood 2007). In practice, this simply means providing the animals with a naturalistic enclosure (resembling the habitat that will be encountered in the wild), for variable periods of time prior to release, rather than standard zoo cages. The aim of pre-conditioning may be to induce development of specific behaviours, such as foraging (e.g. Soderquist \& Serena 1994, Maxwell \& Jamieson 1997), or simply to induce familiarity with the natural habitat and to encourage 'natural' behaviour (e.g. Beck 1991). One expected outcome of this approach might be that animals that are familiar with their natural environment are more likely to explore 'appropriately', less likely to make excessive postrelease movements and less likely to wander into unsuitable habitats. For example, black-footed ferrets Mustela nigripes pre-conditioned in naturalistic enclosures moved shorter distances post-release than did cage-raised animals (Biggins et al. 1999). Postrelease movements may also be affected by biological factors, such as sex or age (e.g. Moehrenschlager \& Macdonald 2003, L. A. Harrington pers. obs.), or number of generations in captivity (McPhee 2004).

Understanding post-release movements and settlement patterns, and the factors that influence them, are vital for effective monitoring of the animals postrelease and for assessing the probability of population establishment (van Heezik et al. 2009). Assessing the influence of biological factors on movement patterns might also allow selection of the 'best' animals for release, and testing the effect of pre-release treatments (or pre-conditioning) allows refinement of strategies in an adaptive management approach (e.g. McCarthy et al. 2012), both of which may lead to increased success in future releases. However, although reintroduction monitoring has improved in recent years (Seddon et al. 2007), systematic studies of the post-release behaviour of reintroduced animals are still lacking in the reintroduction literature. Similarly, although pre-conditioning techniques are relatively common, few scientific papers have included experimental tests of the effectiveness of these methods (Harrington et al. 2013). In a review of 199 published reintroduction projects, Harrington et al. (2013) found that fewer than half reported post- release movements of animals, fewer than $20 \%$ reported monitoring home range establishment and settlement of release animals, and only $11 \%$ of those using supportive measures of some kind (which included pre-conditioning methods but also predator-avoidance training, use of on-site enclosures and various types of post-release support, such as food provisioning) reported experimental tests of the effectiveness of the supportive measures adopted or comparisons of alternate approaches.

We analysed the post-release movements of captive-bred European mink Mustela lutreola reintroduced to Hiiumaa Island, Estonia. The European mink is a small (ca. $1 \mathrm{~kg}$ ), slender, semi-aquatic mustelid that inhabits riparian zones (usually within $100 \mathrm{~m}$ of the riverbank) in forested landscapes (Danilov \& Tumanov 1976, Zuberogoitia \& Zabala 2003, Sidorovich 2011). Once found across most of Europe, European mink are now Critically Endangered and currently exist only in isolated, fragmented populations over a fraction of their former range (Maran et al. 2011). European mink are threatened by habitat loss and fragmentation, and, notably, inter-specific competition with the invasive American mink Neovison vison (Maran et al. 1998, 2011, Sidorovich et al. 1999, Sidorovich \& Macdonald 2001, Zabala et al. 2006, 2007), which is now widespread throughout Europe and the post-Soviet states (Macdonald \& Harrington 2003). European mink are thought likely to be the next mammalian extinction unless effective conservation strategies are put in place (Macdonald et al. 2002). The aim of the Hiiumaa experiment was to create an island sanctuary for European mink, free from the negative impact of the American mink (which had been removed from the island prior to the release of European mink, see Macdonald et al. 2002, Maran 2006). Prior to release, a subset of animals had been raised in large, naturalistic enclosures while all other animals were kept in smaller, standard zoo enclosures (Maran et al. 2009). We aimed to test the effect of pre-release enclosure type on post-release movements of European mink. We predicted (1) that animals raised in larger naturalistic enclosures would make shorter post-release movements and establish home ranges more quickly, and (2) that animals that moved further would have a lower probability of survival.

To explore the possible effect of other biological factors on post-release movements, and to describe the settlement process, we also asked the following questions: (1) Do sex, number of generations in captivity, pregnancy or age affect post-release movements? (2) How do post-release movements change 
over time? Finally, for a subset of animals, we monitored diel activity patterns for comparison with wild European mink.

\section{MATERIALS AND METHODS}

\section{Study area}

Hiiumaa Island $\left(1019 \mathrm{~km}^{2}\right)$ is located in the Baltic Sea (ca. $58^{\circ} \mathrm{N}, 23^{\circ} \mathrm{E}$; Fig. 1), $22 \mathrm{~km}$ from the mainland and at least $5 \mathrm{~km}$ from the nearest large island. Forest covers around $70 \%$ of the island. Rivers and canals total ca. $326 \mathrm{~km}$ and drainage ditches ca. $100 \mathrm{~km}$, and 13 lakes are found on the island (total shoreline length ca. $25 \mathrm{~km}$ ). The human population of the island is around 11000 , almost half of whom reside in the single town on the island (Kärdla; Fig. 1) and in larger villages; the rest of the human population is in dispersed settlements throughout the island. There is little human presence along the rivers. Island climate and fauna are described by Maran et al. (2009).

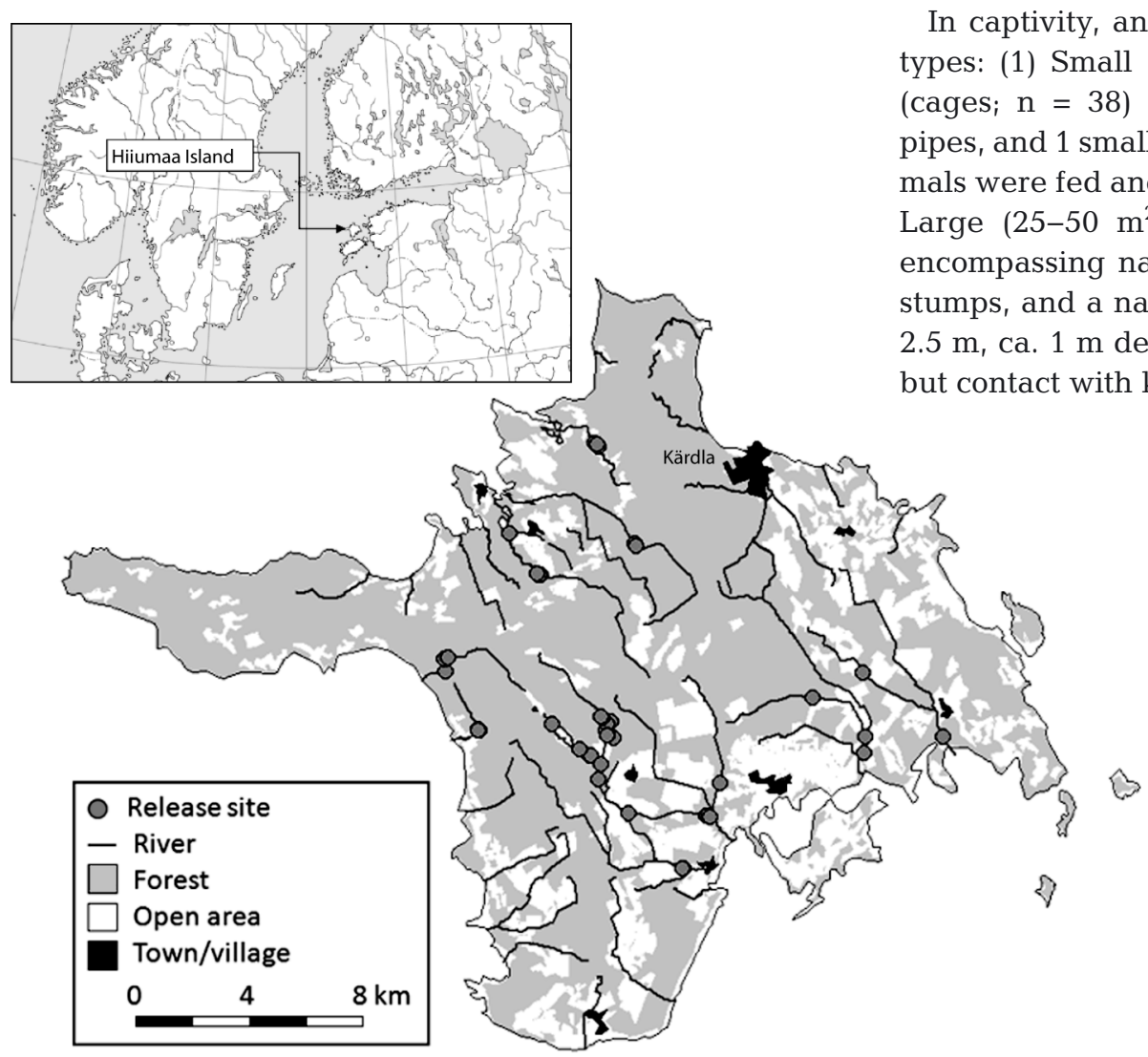

Fig. 1. Location of European mink Mustela lutreola release sites on Hiiumaa Island, Estonia, 2000-2002

\section{Animal origin}

All European mink released on Hiiumaa Island were born at Tallinn Zoological Gardens (see Maran et al. 2009). As part of a larger conservation project, 172 mink were released over 4 yr (2000 to 2003); 52 (20 male, 32 female) of these were released with radiocollars in 2000 to 2002 and tracked for up to 6 mo after release. From here on we refer only to those animals released with radiocollars in the first $3 \mathrm{yr}$ of the project, and their movements in the first 3 mo post-release (individual animal details are given in Table S1 in the Supplement at www.int-res. com/articles/suppl/n024p137_supp.pdf).

The number of generations in captivity of released radiotracked mink varied between 1 and 7.5 (average length of pedigree lineages of all ancestors of a given individual, calculated with SPARKS v1.55 software, ISIS 2007; Table S1), categorised as $<4$ and $>4$ for analysis.

\section{Release methodology}

In captivity, animals were kept in enclosures of 2 types: (1) Small $(2 \times 4 \mathrm{~m})$ standard zoo enclosures (cages; $\mathrm{n}=38$ ) furnished with a few stumps and pipes, and $1 \mathrm{small}$ pool $(30 \times 50 \mathrm{~cm}, 25 \mathrm{~cm}$ deep). Animals were fed and enclosures were cleaned daily. (2) $\left(25-50 \mathrm{~m}^{2}\right)$ naturalistic enclosures $(\mathrm{n}=14)$ $.5 \mathrm{~m}$, ca. $1 \mathrm{~m}$ deep). Food was provided once a day ut contact with keepers was minimal.

All adults had been housed alone from the age of ca. 3 mo, and those kept in the large enclosures had been transferred there ca. 1 yr prior to release. Juveniles were born in their enclosures and kept there with their mother and her other kits until release (at ca. 3 months of age).

Animals were transported ca. $150 \mathrm{~km}$ (a 4 to $5 \mathrm{~h}$ trip, including $1.5 \mathrm{~h}$ on a ferry) from Tallinn Zoological Gardens to the release sites on Hiiumaa Island and released immediately upon arrival in suitable riparian habitat (next to the river, in forested areas, and at least $1 \mathrm{~km}$ from 
human settlements). Individual mink were released at least ca. $2 \mathrm{~km}$ apart. No supplementary food or shelter was provided. In subsequent years, individuals were released in suitable habitat in areas where there were no known resident mink (based on the absence of mink tracks along rivers).

Adult mink (1-4 yr of age) were released in May and June $2000(\mathrm{n}=9), 2001(\mathrm{n}=23)$ and $2002(\mathrm{n}=12)$; and in September 2000, 8 juvenile mink (ca. 3 mo old) were released (Table S1). Seven of the 12 adult females released in 2002 were released in their third week of pregnancy (i.e. days 14 to 21 in a 41 to $43 \mathrm{~d}$ pregnancy).

The release was carried out in accordance with the national species recovery plan and followed IUCN Reintroduction Specialist Group guidelines (IUCN 1998). Due consideration was given to animal welfare at all stages.

\section{Radiotracking}

Mink were equipped with radiocollars (Biotrack) weighing $14 \mathrm{~g}$ ( $\leq 3 \%$ of body weight) and tracked using TR-4 (Telonics) and R-1000 receivers (Communication Specialists). Animal locations and distance from suitable aquatic habitat (rivers, canals and lakes, but not ditches, dry rivers and ponds that were considered poor-quality habitat) were recorded 1 to 3 times a day during the first week post-release (where possible, i.e. when animals were successfully located), every day during the following $20 \mathrm{~d}$, and once every 2 d during the second to third month postrelease. For 6 animals, hourly locations and activity were recorded over 1 to $6 \mathrm{~d}$ (within the first 2 mo post-release). Animal locations were obtained by homing in (estimated accuracy $20 \mathrm{~m}$ ). In open terrain, the signals were detectable at ca. $1 \mathrm{~km}$, and in woodland at ca. $600 \mathrm{~m}$. Animals were recorded as 'active' when they were moving or 'inactive' when they were stationary. The lifespan of transmitters was ca. 6 mo, but some failed prematurely or were lost (Table S1). Additional survival data (see Table S1) were obtained from bi-annual live-trapping (reported by Maran et al. 2009); animals lost to radiotracking and not subsequently recaptured were assumed to be dead.

\section{Analyses}

To quantify post-release movements and compare amongst individuals when tracking times were variable and, in some cases, short (due to deaths and losses of animals; Table S1), we measured movements (details in Table 1) at different stages of the initial post-release period: at $3 \mathrm{~d}$ post-release, and during the first $2 \mathrm{wk}, 1 \mathrm{mo}$ and 1 to 3 mo postrelease. Thus, for analyses at each stage, sample size differed depending on the number of animals that were still alive and being radiotracked (Table 2). To test the relationship between movements and survival, we used survival to 1 mo (S_1mo; a binary variable) because the probability of survival tended to stabilise after the first 1 to 1.5 mo following a period of very high mortality in the first few days post-release (see Maran et al. 2009), and minimum number of days survived (mins; data in Table S1). To assess how movements changed over time, we plotted daily displacement from the release site $(\mathrm{dD}$; Table 1$)$ for all individuals that survived and were radiotracked for at least $1 \mathrm{mo}$; 'settlement' was defined as stabilisation of dD (as in Sjöåsen 1997). Activity (quantified as the proportion of active fixes within a $4 \mathrm{~h}$ period) was plotted against hours of the day.

Experimental design was constrained by the availability of animals in captivity and the need to maintain genetic diversity within the captive founder population; consequently, age, sex and pregnancy status were not distributed evenly across years (see Table S1). We first tested for potentially confounding year effects using 2 subsets of the data that were comparable across years: 1 yr olds in 2000 versus 2001, and adult (age 1-4 yr) non-pregnant females in 2001 versus 2002. No significant differences (Mann-Whitney test, $\mathrm{p}>0.05$ in all cases) were detected between years for any of the movement parameters; therefore, years were combined for further analysis. To remove further confounding effects, the data were split into the following subsets:

(1) Non-pregnant $1 \mathrm{yr}$ olds to test the effect of sex and enclosure type $(\mathrm{n}=25,20,10$, at $3 \mathrm{~d}, 2 \mathrm{wk}$ and 1 mo post-release, respectively).

(2) Non-pregnant adults released from standard zoo enclosures to test the effect of number of generations in captivity ( $\mathrm{n}=24$ and 17 at $3 \mathrm{~d}$ and 2 wk postrelease, respectively).

(3) Females released in 2002 from standard zoo enclosures to test for pregnancy effects ( $\mathrm{n}$ in Table 2).

(4) All older animals ( $\geq 2 \mathrm{yr}$ ), and juveniles released in September 2000, as 2 separate datasets, both compared with 1 yr olds of the same sex, to explore the effect of age (although for juveniles it was not possible to distinguish between age and season effects) (n in Table 2). 
Table 1. Descriptions of post-release movement parameters measured for European mink Mustela lutreola released on Hiiumaa Island, Estonia, the post-release stage at which each was measured and the factor effects tested for each parameter (S: sex; E: enclosure type; G: number of generations in captivity; P: pregnancy; A: age)

\begin{tabular}{|c|c|c|c|c|}
\hline Parameter & Notation & Description & $\begin{array}{l}\text { Post-release } \\
\text { stage }\end{array}$ & $\begin{array}{l}\text { Effects } \\
\text { tested }\end{array}$ \\
\hline $\begin{array}{l}\text { Net displacement from } \\
\text { the release site }\end{array}$ & ND & $\begin{array}{l}\text { Euclidean distance from the release site }(\mathrm{m}) \\
\text { at } 3 \mathrm{~d} \text { or } 2 \mathrm{wk} \text { post-release }\end{array}$ & $\begin{array}{c}3 \mathrm{~d} \\
2 \mathrm{wk}\end{array}$ & $\begin{array}{l}\mathrm{S}, \mathrm{E}, \mathrm{G}, \mathrm{P}, \mathrm{A} \\
\mathrm{S}, \mathrm{E}, \mathrm{G}, \mathrm{A}\end{array}$ \\
\hline $\begin{array}{l}\text { Maximum displacement } \\
\text { from the release site }\end{array}$ & $\mathrm{MD}$ & $\begin{array}{l}\text { Maximum Euclidean distance from the release } \\
\text { site }(\mathrm{m}) \text { during the first } 3 \mathrm{~d} \text { or } 2 \mathrm{wk} \text { post-release }\end{array}$ & $\begin{array}{c}3 \mathrm{~d} \\
2 \mathrm{wk}\end{array}$ & $\begin{array}{l}\mathrm{S}, \mathrm{E}, \mathrm{G}, \mathrm{P}, \mathrm{A} \\
\mathrm{S}, \mathrm{E}, \mathrm{G}, \mathrm{A}\end{array}$ \\
\hline $\begin{array}{l}\text { Daily displacement from } \\
\text { the release site } \mathrm{a}^{\mathrm{a}}\end{array}$ & $\mathrm{dD}$ & $\begin{array}{l}\text { Euclidean distance from the release site }(\mathrm{m}) \text { each } \\
\text { day for the duration of the monitoring period }\end{array}$ & $1-3 \mathrm{mo}$ & $\mathrm{S}, \mathrm{E}$ \\
\hline $\begin{array}{l}\text { Inter-day movements } \\
\quad(\text { daily distance moved })^{\mathrm{a}}\end{array}$ & $\mathrm{DD}$ & $\begin{array}{l}\text { Net Euclidean distance moved between one day } \\
\text { and the next during the first } 2 \mathrm{wk} \text { post-release } \\
\text { (calculated as median and maximum) }\end{array}$ & $2 \mathrm{wk}$ & $\mathrm{S}, \mathrm{E}, \mathrm{G}, \mathrm{A}$ \\
\hline $\begin{array}{l}\text { Proximity to suitable } \\
\text { aquatic habitat }\end{array}$ & proxAH & $\begin{array}{l}\text { Individuals classified as }<25 \mathrm{~m} \text { or }>25 \mathrm{~m}^{\mathrm{b}} \text { from } \\
\text { rivers, canals, lakes or coast at } 3 \mathrm{~d} \text { post-release }\end{array}$ & $3 d$ & $\mathrm{~S}, \mathrm{E}, \mathrm{G}, \mathrm{A}$ \\
\hline $\begin{array}{l}\text { Proportion of time spent close } \\
\text { to suitable aquatic habitat }\end{array}$ & propAH & $\begin{array}{l}\text { Proportion of locations }<25 \mathrm{~m} \text { from rivers, canals, } \\
\text { lakes or coast during the first } 2 \mathrm{wk} \text { post-release }\end{array}$ & $2 \mathrm{wk}$ & $\mathrm{S}, \mathrm{E}, \mathrm{G}$ \\
\hline Area used ${ }^{c}$ & $\mathrm{AU}$ & $\begin{array}{l}\text { Estimated using restricted edge (concave) polygons } \\
\text { with a restriction distance at } 60 \% \text { of range span } \\
\text { (i.e. the minimum value that did not result in } \\
\text { fragmentation of the area) })^{\mathrm{d}}\end{array}$ & $1 \mathrm{mo}$ & $\mathrm{S}, \mathrm{E}, \mathrm{A}$ \\
\hline Activity $^{\mathrm{e}}$ & & $\begin{array}{l}\text { Proportion of active fixes within a } 4 \mathrm{~h} \text { period } \\
\text { over } 24 \mathrm{~h}\end{array}$ & $\leq 2 \mathrm{mo}$ & - \\
\hline
\end{tabular}

Table 2. Numbers of European mink Mustela lutreola released and monitored on Hiiumaa Island, Estonia, at each of 4 stages post-release ( $3 \mathrm{~d}, 2 \mathrm{wk}, 1 \mathrm{mo}$, up to $3 \mathrm{mo}$ ) according to sex, pre-release enclosure type, number of previous generations in captivity, pregnancy and age group, and their fate (predated, dead or lost). Not all individuals that survived and were monitored for $\geq 3 \mathrm{~d}$ (total $=49$ ) were successfully located on Day 3 , so sample sizes for tests using $3 \mathrm{~d}$ movement parameters (see Table 1) were lower than the total that survived for this period (maximum possible sample size $=43$ ). Total numbers monitored at 1 mo include 2 mink tracked for 26 to 27 d; another individual was later confirmed to have survived $>1$ mo but was not included. The last stage includes all individuals that were tracked for $\geq 30 \mathrm{~d}$. Individual histories and fates are given in Table S1 in the Supplement

\begin{tabular}{|c|c|c|c|c|c|}
\hline \multirow[t]{2}{*}{ Factor } & \multirow[t]{2}{*}{ Released } & & \multicolumn{2}{|c|}{ Post-release stage } & \multirow[b]{2}{*}{ Up to $3 \mathrm{mo}$} \\
\hline & & $3 \mathrm{~d}$ & $2 \mathrm{wk}$ & $1 \mathrm{mo}$ & \\
\hline Sex (male, female) & 20,32 & 19,30 & 14,16 & 9,8 & 6,8 \\
\hline Enclosure type (zoo cage, naturalistic) & 38,14 & 35,14 & 18,12 & 7,10 & 6,8 \\
\hline Generations in captivity $(<4,>4)$ & 44,8 & 41,8 & 25,5 & 16,1 & - \\
\hline Pregnant (yes, no) ${ }^{\mathrm{a}}$ & 7,5 & 6,5 & 2,3 & 2,1 & - \\
\hline Age (juvenile, 1 yr, $\geq 2$ yr) ${ }^{b}$ & $8,33,11$ & $7,33,10$ & $3,22,5$ & $3,12,2$ & - \\
\hline Predated & - & 1 & 10 & 14 & 15 \\
\hline Dead (other ${ }^{\mathrm{C}}$ ) & - & 1 & 3 & 5 & 5 \\
\hline Lost & - & 1 & 9 & 16 & 18 \\
\hline
\end{tabular}

Because sample sizes were small and the design was unbalanced, we used non-parametric statistical tests throughout and tested the effect of each factor separately using appropriate subsets of the data (as above); we were unable to test statistically for inter- actions between factors. To explore the effect of age, movements of individual older ( $\geq 2 \mathrm{yr})$ animals and individual juveniles were compared with $95 \%$ confidence intervals for medians for $1 \mathrm{yr}$ olds of the same sex (values falling outside the confidence intervals 
were considered to deviate significantly from $1 \mathrm{yr}$ olds' movements). Statistical analyses were carried out in Minitab 13 (www.minitab.com) or in R (version 2.13.0, R Development Core Team 2011); specific tests used are given in the text. Statistical significance was accepted at $\mathrm{p} \leq 0.05$.

\section{RESULTS}

Radiolocations of released mink were obtained on an average of $21.8 \mathrm{~d}$ each (range: 2-67 d) over individual monitoring periods of $1 \mathrm{~d}$ to 3 mo (total radiolocations: 2248 ; mean \pm SD: $43.0 \pm 19.0$, per individual; Table S1). Of 52 individuals, 49 (94\%) survived and were monitored for the first 3 full days postrelease, $30(58 \%)$ for the first $2 \mathrm{wk}$ and $15(27 \%)$ for $\geq 1 \mathrm{mo}$. Average mins (estimated from live-trapping data; Table S1) was $101.3 \mathrm{~d}$ (range: 1-1180 d). At the end of the study in August 2002, 21 animals (40\%) were confirmed dead (16 due to predation), 25 (48\%) were lost (due to collar or signal loss), and $6(12 \%)$ were known to be alive (Table S1).

Over the 3 mo monitoring period, 13 animals moved $>10 \mathrm{~km}$ from their release site (maximum: $32.3 \mathrm{~km}$ ), and 22 animals remained within $5 \mathrm{~km}$ of the release site. During the first $2 \mathrm{wk}$ post-release, 24 of 27 ind. were found $\geq 100 \mathrm{~m}$ away from suitable aquatic habitat, or $<25 \mathrm{~m}$ from poor-quality aquatic habitat, on at least 1 occasion. Inter-day movements (daily distance moved, DD, Table 1) ranged between 0 and $23.7 \mathrm{~km}$ (median: $375 \mathrm{~m}$ ), and median DD differed significantly among individuals (KruskalWallis: all adult mink, $H_{26}=56.95, \mathrm{p}<0.001, \mathrm{n}=27$; non-pregnant 1 yr olds, $H_{19}=42.96, \mathrm{p}=0.001, \mathrm{n}=20$ ). The area used in the first month post-release (AU, Table 1) ranged between 27 and $>8000$ ha (median: 797 ha, $\mathrm{n}=17$, Fig. 2).

\section{Enclosure effect}

We did not detect an enclosure effect on short-term ( $3 \mathrm{~d}$ or $2 \mathrm{wk}$ ) post-release distances moved (ND, maximum displacement [MD] or DD, Table 3, Fig. 2), but individuals from large naturalistic enclosures spent significantly less time close to water over the first 2 wk post-release than did animals from standard zoo enclosures (median propAH, for animals from naturalistic enclosures: $0.21, \mathrm{n}=7$; for animals from standard zoo enclosures: $0.51, \mathrm{n}=10$; Mann-Whitney: $W=113, \mathrm{p}=0.028$; and there was some evidence that they were more often found $>25 \mathrm{~m}$ from aquatic habitat at $3 \mathrm{~d}$ post-release: $\chi^{2}=2.50, \mathrm{p}=0.114$ ). There was also a slight tendency for animals from large, naturalistic enclosures to have covered a larger area by 1 mo post-release than animals from standard zoo enclosures (median AU = 829 ha and 144 ha, respectively, excluding 1 ind. that moved over an area $>8000$ ha), although the difference was not statistically significant (Mann-Whitney: $W=24, \mathrm{p}=0.126$, Table 3, Fig. 2; the trend was true for both sexes).

\section{Biological factors}

With the exception of 1 wide-ranging female (that moved $2.9 \mathrm{~km}$ ), males moved further than females in the first $3 \mathrm{~d}$ post-release $(3 \mathrm{~d}$ ND: Mann Whitney: $W=$ $35, \mathrm{p}=0.035 ; 3 \mathrm{~d}$ MD: $W=36, \mathrm{p}=0.041 ; 1$ outlying female removed, Table 3, Fig. 2) but no sex effect was detected after $3 \mathrm{~d}$ (there was an apparent, but not significant, trend for males to have covered larger areas at 1 mo post-release, but only 4 non-pregnant adult females remained in this dataset; see Table 3, Fig. 2).

We did not detect a generation effect at $3 \mathrm{~d}$ or $2 \mathrm{wk}$ post-release, or a pregnancy effect at $3 \mathrm{~d}$ postrelease. Sample size was insufficient to test for pregnancy effects at 2 wk or 1 mo post-release, or generation effects 1 mo post-release.

All juveniles released in September moved significantly further (as measured by MD) in the first $3 \mathrm{~d}$ post-release than $1 \mathrm{yr}$ olds released in June (male juvenile range: $2849-5870 \mathrm{~m}, \mathrm{n}=4 ; 95 \%$ CI for median of male 1 yr olds: $695,2716 \mathrm{~m}, \mathrm{n}=13$; female juvenile range: $1795-6223 \mathrm{~m}, \mathrm{n}=3 ; 95 \%$ CI for median of female $1 \mathrm{yr}$ olds: $544,1402 \mathrm{~m}, \mathrm{n}=12$ ); this was also true for ND for all but one of 7 juveniles. The 3 juveniles that survived $2 \mathrm{wk}$ also all made significantly longer maximum (not median) DD movements than did the 1 yr olds, perhaps suggesting more erratic movements (juvenile range: 6252-11296 m; $95 \%$ CI for male 1 yr olds: 1612, $3653 \mathrm{~m}, \mathrm{n}=11 ; 95 \%$ CI for female 1 yr olds: $1364,5479 \mathrm{~m}, \mathrm{n}=9$ ), although this was not the case for 2 wk ND or MD. There was no significant difference in AU between these 3 juveniles and the adults (Mann-Whitney: $W=83.0, \mathrm{p}=$ 0.0712 ), but all 3 moved over $>1000$ ha, whereas 11 of 14 adults used $<1000$ ha. We detected no general trend in $3 \mathrm{~d}$ or $2 \mathrm{wk}$ distances moved by older animals in comparison with $1 \mathrm{yr}$ olds of the same sex, except that older animals $(n=10)$ were significantly more likely to be found close to water $(<25 \mathrm{~m})$ at $3 \mathrm{~d}$ than were $1 \mathrm{yr}$ olds $(\mathrm{n}=31)$ or juveniles $(\mathrm{n}=7$; Fisher's exact test: $p=0.021$ ); there was no apparent relationship between age and propAH. 

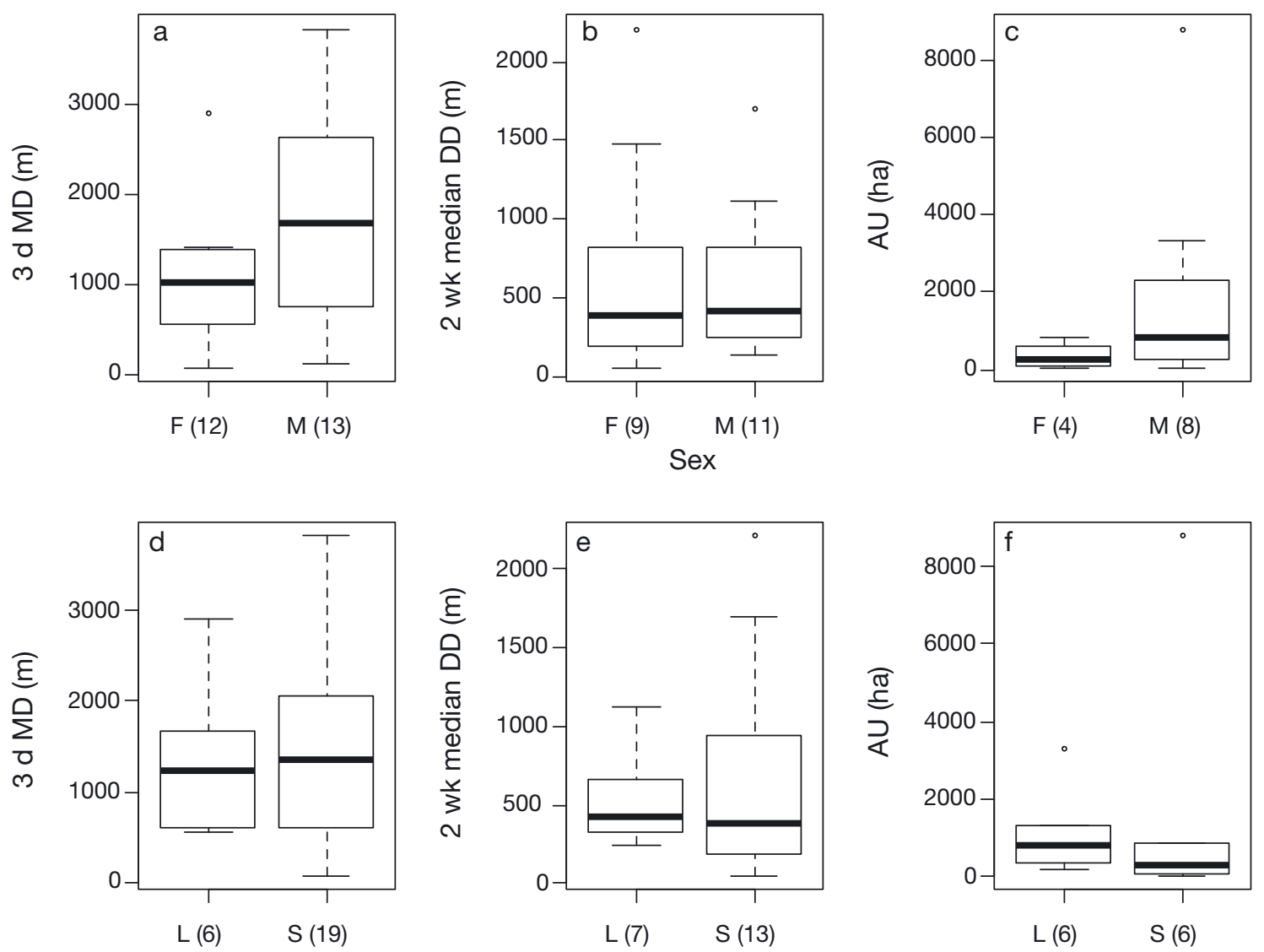

Enclosure type

Fig. 2. Movements of captive-bred European mink Mustela lutreola on Hiiumaa Island, Estonia, showing the effect of $(\mathrm{a}, \mathrm{b}, \mathrm{c})$ sex and $(d, e, f)$ pre-release enclosure type at $(a, d) 3 d,(b, e) 2$ wk and $(c, f) 1$ mo post-release. Box plots show median, interquartile range, range excluding outliers and outliers. MD: maximum displacement from the release site (m); DD: daily distance moved (m); AU: area used (ha) (see Table 1 for details). F: female; M: male; L: large naturalistic enclosures; S: standard zoo enclosures (see 'Materials and methods'). Sample sizes are given in parentheses. Two 2 yr old animals were included in the dataset at 1 mo post-release to increase sample size

Table 3. Distances moved post-release by male and female European mink Mustela lutreola raised in standard zoo enclosures and large naturalistic enclosures, at $3 \mathrm{~d}, 2$ wk and 1 mo post-release. Data are median (range, outlier*). Data that are significantly different are highlighted in bold (details are given in the 'Results'). Codes for movement parameters are given in Table 1 ; for descriptions of enclosure types see 'Materials and methods'

\begin{tabular}{|c|c|c|c|c|c|}
\hline Factor & & $\begin{array}{c}3 \mathrm{~d} \\
\mathrm{ND}(\mathrm{m}) \\
{[\mathrm{MD}(\mathrm{m})]}\end{array}$ & $\begin{array}{c} \\
\mathrm{ND}(\mathrm{m}) \\
{[\mathrm{MD}(\mathrm{m})]}\end{array}$ & $\overline{\text { Median DD (m) }}$ & $\begin{array}{c}1 \mathrm{mo} \\
\mathrm{AU}(\mathrm{ha})\end{array}$ \\
\hline \multirow[t]{2}{*}{ Sex } & Male & $\begin{array}{c}1395(19-3833) \\
{[1680(138-3833)]}\end{array}$ & $\begin{array}{c}7241(300-14580) \\
{[7896(1126-22920)]}\end{array}$ & 422 (139-1699) & $797\left(48-3303,8795^{*}\right)$ \\
\hline & Female & $\begin{array}{c}544\left(0-1406,2907^{*}\right) \\
{\left[904\left(73-1406,2907^{*}\right)\right]}\end{array}$ & $\begin{array}{c}1998(160-10310) \\
{[3890(1238-10310)]}\end{array}$ & $385(51-2210)$ & $296(32-861)$ \\
\hline \multirow[t]{2}{*}{ Enclosure type } & Small & $\begin{array}{c}1114(0-3833) \\
{[1360(73-3833)]}\end{array}$ & $\begin{array}{c}1998(160-12160) \\
{[6041(1126-22920)]}\end{array}$ & $385(51-2210)$ & $144\left(32-872,8795^{*}\right)$ \\
\hline & Large & $\begin{array}{c}1086(544-2924) \\
{[1231(544-2924)]}\end{array}$ & $\begin{array}{c}7241(365-14580) \\
{[7276(1238-14580)]}\end{array}$ & $422(246-1118)$ & $829(176-3303)$ \\
\hline
\end{tabular}




\section{Survival}

Three day movements did not differ statistically between those animals that survived 1 mo and those that did not ( $3 \mathrm{~d}$ ND: non-survivors median: $1.11 \mathrm{~km}$; survivors median: $1.45 \mathrm{~km}$; Mann Whitney: $W=635$, $\mathrm{p}=0.948 ; 3 \mathrm{~d}$ MD: non-survivors median: $1.27 \mathrm{~km}$; survivors median: $1.67 \mathrm{~km}$; $W=$ $640, \mathrm{p}=0.969, \mathrm{n}=29,14)$. There was no association between proxAH and $\mathrm{S} \_1 \mathrm{mo}$ (Fisher's exact test: $\mathrm{p}=1.0$ ), nor was there any correlation between either $3 \mathrm{~d}$ ND or MD and $\operatorname{minS}(\mathrm{r}=-0.131, \mathrm{p}=0.420 ; \mathrm{r}=$ $-0.124, \mathrm{p}=0.447$, respectively, $\mathrm{n}=40$, juveniles excluded) or between median or maximum DD and $\operatorname{minS}(\mathrm{r}=-0.229, \mathrm{p}=$ $0.250 ; \mathrm{r}=-0.262, \mathrm{p}=0.187$, respectively, $\mathrm{n}=27$, juveniles excluded).

\section{Settlement}

The pattern of $\mathrm{dD}$ from the release site over time varied among individuals ( $\mathrm{n}=$ 13; Fig. 3), and it was not possible to quantify the 'time to settlement' for all individuals (some individuals appeared to settle within $10 \mathrm{~d}$, others did not show any obvious stabilisation over $3 \mathrm{mo}$ ) or to test statistically for the effect of sex or enclosure type. Females appeared to settle closer to the release site than did males, but there was no obvious effect of enclosure type (Fig. 3). Three distinct settlement patterns were apparent: (1) moving progressively further from the release site over time, settling at some distant point (usually in $10 \mathrm{~d}$ or less), (2) staying close to the release site, using a very small area (for the first 20 to $40 \mathrm{~d}$ post-release), progressively increasing exploration and the size of the area used, (3) using (or exploring) a large area centred around the release site. The movements of some individuals (e.g. no. 4) did not fit any of these patterns, and this animal was still moving between the release site and up to $16 \mathrm{~km}$ away in the second month post-release.

\section{Activity}

Activity was between 23 and $56 \%$ active fixes (per $4 \mathrm{~h}$ period; $\mathrm{n}=6$ ind., $1-6 \mathrm{~d}_{\text {ind. }}{ }^{-1}$ ). It appeared to be lowest between 04:00 and 08:00 h, but was otherwise fairly consistent day and night (Fig. 4).

\section{DISCUSSION}

Contrary to our predictions, the distances moved by animals raised in large naturalistic enclosures (hereafter enclosures) were no shorter than were those made by animals raised in standard zoo enclosures (hereafter cages), nor did they appear to settle any sooner. Moreover, time spent close to water, a metric that we considered indicative of adaptive behaviour in a semi-aquatic animal, was lower for animals raised in enclosures than for those from 
cages, and there was some suggestion that the area used in the first month after release by mink from enclosures was actually larger than that used by mink from cages (discussed below). Also contrary to our predictions, we found no relationship between distance moved and survival.

We were unable to detect a consistent effect of any of the biological factors tested on post-release movements (although males appeared to move farther than females initially, there was no clear difference between the sexes during later stages of the release). There was some evidence that juveniles released in September moved farther from the release site and ranged over a larger area than adults released earlier in June, but it was not possible to separate the effect of age and time of year. Taking a precautionary approach, the release of juveniles in September was discontinued for European mink recovery on Hiiumaa. Interestingly, older animals (2 to $4 \mathrm{yr}$ old) did not appear to move differently than 1 yr olds, and we did not detect any difference in movements for those animals that were from long captive lineages (6 to 7 generations). These findings should be confirmed with further research (given the small sample sizes available to test these effects; Table 2) but have potentially useful implications for the management of captive mink populations and are consistent with Maran et al. (2009), who found no significant impact of history of captivity or age on survival.

The areas used by some of the released mink were considerably greater than the home ranges of wild European mink in Belarus (ca.100-700 ha, also estimated using concave polygons; Sidorovich 2011) or of home range sizes reported for reintroduced mink in Germany (ca.1-500 ha, calculated using kernel density estimates; Peters et al. 2009) over a longer period (up to 300 d). Released European mink ate a wide variety of atypical prey in the first $10 \mathrm{~d}$ post-release (Põdra et al. 2013a), thus, the large areas used initially

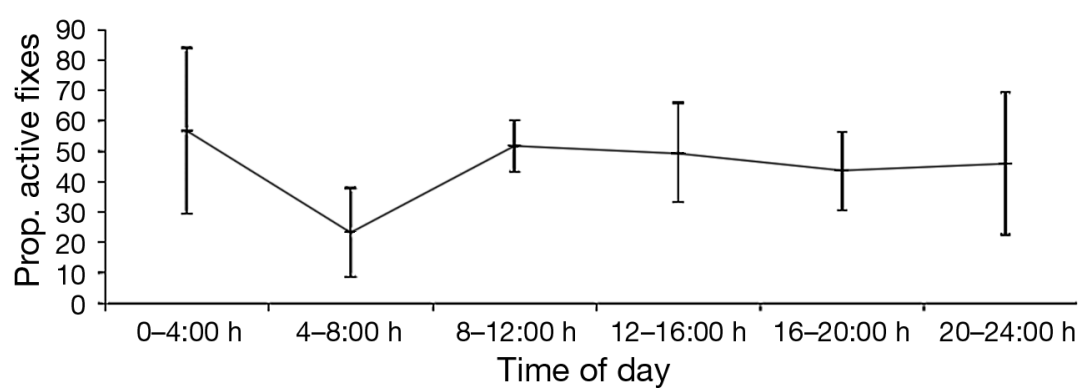

Fig. 4. Daily activity of captive-bred European mink Mustela lutreola reintroduced on Hiiumaa Island, Estonia showing proportion of active fixes to the total number of fixes. Data are means $\pm \mathrm{SD}$, for a subset of 6 animals radiotracked hourly over $24 \mathrm{~h}$, for 1 to $6 \mathrm{~d}$ within the first 2 mo post-release may be due to searching for prey over a variety of habitats. Indeed, although all individuals were released at least $1 \mathrm{~km}$ from human settlements, they were frequently found near human dwellings and, in the first month post-release, 11 attacks were recorded on domestic animals (chickens, rabbits, kittens). Diet tended to shift to a more typical mink diet in the second month post-release (Põdra et al. 2013a); however, we found no evidence that the area used in the second month was consistently smaller than that used in the first.

Some animals appeared to settle immediately or within $10 \mathrm{~d}$, whereas others showed no sign of settling in the first 3 mo post-release. Determining the time to settle is not analytically straightforward because the most appropriate method to use depends on the pattern of establishment, which was not consistent among individuals in this case. Incremental analysis based on home range estimators (e.g. Macdonald et al. 2002) is only appropriate if an individual increases the area used over time and will otherwise underestimate the time to settle. Stabilisation of the distance from the release site (method used in the present study following Sjöåsen 1997) may be preferable but is also flawed because the definition of 'stable' (i.e. the expected variation in distance from the release site) is dependent on expected home range size. Thus, estimation of time to settle and size of 'established' home range becomes circular. If we consider movements within an area between the release site and $4 \mathrm{~km}$ distant to be reasonable for a mink, several individuals could be said to have settled and established a home range at the release site almost immediately post-release (Fig. 3), and, in fact, $4 \mathrm{~km}$ is within the reported maximal home range length for wild European mink (Sidorovich 2011).

The lack of enclosure effect on short-term movements might be interpreted as the enclosures lacking the appropriate stimulus for the development of familiarity, or preference, for the local habitat (Stamps \& Swaisgood 2007, Roe et al. 2010) or that the cage environment at Tallinn Zoo was sufficient. Alternatively, the facts that enclosure animals were more often found further from aquatic habitats, did not make longer daily movements, but appeared to cover slightly larger areas over time, suggest that enclosure animals may simply have been exploring more (and were perhaps better prepared for 'learning' about their new environment than 
were caged animals, see e.g. Eliassen et al. 2007, Berger-Tal \& Avgar 2012). Whether, or how, such exploration (if it occurs) links to survival is not clear, but survival was marginally higher for animals raised in enclosures compared with those raised in cages (Maran et al. 2009).

Regardless of enclosure type, the fact that there was no relationship between post-release movements (at $3 \mathrm{~d}$ and $2 \mathrm{wk}$ post-release) and survival demonstrates that we currently lack the information required to explain why some animals survive and some do not. The proximate cause of mortality for the majority of released European mink was predation (thought to be mostly foxes or dogs, Põdra et al. 2013b), but the ultimate cause (i.e. why the mink were vulnerable to predation) is unclear. Non-survivors do not appear to move greater distances than survivors but perhaps behave inappropriately otherwise. Inappropriate behaviours that expose an animal to predation have been observed in a number of other captive-bred species when released into the wild (Biggins et al. 1998, Rantanen et al. 2010a,b, Jones \& Merton 2012), and are usually as simple as being active for too long, in the wrong place or at the wrong time. Activity of a sub-set of released mink did not appear to differ substantially from that of wild European mink (although released mink appeared to be more active during the day than might be expected for wild mink, see e.g. Garin et al. 2002, Sidorovich 2011). Overall activity levels were relatively low (compared with, for example, 40 to $60 \%$ active fixes for wild mink in Belarus; Sidorovich 2011), but we are unable to describe 'how' the animals moved and whether they behaved like wild animals when they moved (e.g. by moving quickly between areas of cover). It is difficult to directly observe elusive animals like the European mink, but the daily locational data obtained from radiotracking in this study was not sufficiently informative to elucidate the mechanism of vulnerability to predation. More detailed (minute-by-minute) analysis of movements might offer further insight, and we suggest that the behaviour of released mink, as well as the development of natural behaviour in captivity, warrants additional attention (see Buchholz 2007, Lindell 2008). Specific behaviours of interest might include fine-scale habitat associations during hunting (with a view to both prey abundance and vulnerability to predation), escape reactions, and more detailed temporal activity patterns (compared with activity patterns of identified predatory species). Training captive-bred animals to avoid predators, although difficult (McLean et al. 1996, Griffin et al. 2000), may also be a useful tool worth investigating for European mink (e.g. van Heezik et al. 1999, Shier \& Owings 2006, Moseby et al. 2012).

Sample sizes were small throughout and especially so for longer-term movements, and (as for many other reintroductions and translocations; Dickens et al. 2009) we observed considerable differences among individuals in movement parameters and in establishment patterns. Haage et al. (2013) suggested that captive European mink exhibit different 'personalities' (sensu Gosling 2001). Individual personality types may differ in their exploratory or dispersal behaviour (Dingemanse et al. 2003) and/or in their response to predators (Blumstein et al. 2006); therefore, this phenomenon may be worth further consideration in future reintroductions.

Although some mink made extensive (maladaptive) movements post-release, some settled quickly and established apparent home ranges at the release site, indicating that captive-bred European mink can survive in the wild. Indeed, mink have bred on Hiiumaa, and yearly monitoring data show a steady increase in their number, although the population on the island is not yet self-sustaining (T. Maran \& M. Põdra unpubl. data). For the reintroduction of any captive-bred species, we tentatively suggest that collection of more detailed post-release behavioural data to better understand animal fate would be insightful, and that investigation of the potential relationship between personalities and post-release survival (see e.g. Mathews et al. 2005) might provide a useful way forward.

Acknowledgements. This study received financial support from the UK government's Darwin Initiative, EU Life Project No. LIFE2000NAT/EE/7081, Foundation LUTREOLA, Zoos Help Foundation, Bernhandine Foundation, Denver Zoological Society, Thoiry Zoological Park, Apenheul Primate Park, Helsinki Zoo and the Zoological Society for Conservation of Species and Populations. Thanks also to Tallinn Zoo, Rotterdam Zoo and Hiiumaa County Department of the Estonian Ministry of the Environment, A. Kranz, S. Hirst, T. Churher, T. Samad, D. Randall and P. Phillpot, as well as 3 anonymous reviewers.

\section{LITERATURE CITED}

Beck BB (1991) Managing zoo environments for reintroduction. In: Wheeling WV (ed) Proc Annu Meeting of the American Association of Zoological Parks and Aquariums, p 436-440

> Berger-Tal O, Avgar T (2012) The glass is half-full: overestimating the quality of a novel environment is advantageous. PLoS ONE 7:e34578

Biggins DE, Godbey JL, Hanebury LR, Luce B, Marinari PE, Matchett MR, Vargas A (1998) The effect of rearing 
methods on survival of reintroduced black-footed ferrets. J Wildl Manag 62:643-653

> Biggins DE, Vargas A, Godbey JL, Anderson SH (1999) Influence of prerelease experience on reintroduced blackfooted ferrets (Mustela nigripes). Biol Conserv 89:121-129

Biggins DE, Godbey JL, Horton BM, Livieri TM (2011) Movements and survival of black-footed ferrets associated with an experimental translocation in South Dakota. J Mammal 92:742-750

> Blumstein DT, Holland BD, Daniel JC (2006) Predator discrimination and 'personality' in captive Vancouver Island marmots (Marmota vancouverensis). Anim Conserv 9: $274-282$

Buchholz R (2007) Behavioural biology: an effective and relevant conservation tool. Trends Ecol Evol 22:401-407

Cook RP (2004) Dispersal, home range establishment, survival, and reproduction of translocated eastern box turtles, Terrapene c. carolina. Appl Herpetol 1:197-228

Danilov PI, Tumanov IL (1976) The ecology of the European and American mink in the northwest of the USSR. In: Ivanter EV (ed) Ecology of birds and mammals in northwest of the USSR. Akad Nauk Karelski Filial, Inst Biol, Petrozavodsk, p 118-143 (in Russian)

> Davis JM, Stamps JA (2004) The effect of natal experience on habitat preferences. Trends Ecol Evol 19:411-416

> Dickens MJ, Delehanty DJ, Reed JM, Romero LM (2009) What happens to translocated game birds that 'disappear'? Anim Conserv 12:418-425

> Dingemanse NJ, Both C, van Noordwijk AJ, Rutten AL, Drent PJ (2003) Natal dispersal and personalities in great tits (Parus major). Proc R Soc Lond B Biol Sci 270:741-747

Eliassen S, Jørgensen C, Mangel M, Giske J (2007) Exploration of exploitation: life expectancy changes the value of learning in foraging strategies. Oikos 116:513-523

Garin I, Aihartza J, Zubergoitia I, Zabala J (2002) Activity pattern of European mink (Mustela lutreola) in southwestern Europe. Z Jagdwiss 48:102-106

> Gosling SD (2001) From mice to men: What can we learn about personality from animal research? Psychol Bull 127:45-86

Griffin AS, Blumstein DT, Evans CS (2000) Training captivebred or translocated animals to avoid predators. Conserv Biol 14:1317-1326

Haage M, Bergvall UA, Maran T, Kiike K, Angerbjörn A (2013) Situation and context impacts the expression of personality: the influence of breeding season and test context. Behav Processes 100:103-109

> Harrington LA, Macdonald DW (2008) Spatial and temporal relationships between invasive American mink and native European polecats in the southern United Kingdom. J Mammal 89:991-1000

Harrington LA, Moehrenschlager A, Gelling M, Atkinson RPD, Hughes J, Macdonald DW (2013) Conflicting and complementary ethics of animal welfare considerations in reintroductions. Conserv Biol 27:486-500

IUCN (International Union for Conservation of Nature) (1998) Guidelines for re-introductions. IUCN Re-introduction Specialist Group, IUCN, Gland

Jones CG, Merton DV (2012) A tale of two islands: the rescue and recovery of endemic birds in New Zealand and Mauritius. In: Ewen JG, Armstrong DP, Parker KA, Seddon PJ (eds) Reintroduction biology. Integrating science and management. Wiley-Blackwell, Chichester, p 33-72

- Lindell CA (2008) The value of animal behaviour in evaluations of restoration success. Restor Ecol 16:197-203
Macdonald DW, Harrington LA (2003) The American mink: the triumph and tragedy of adaptation out of context. NZ J Zool 30:421-441

Macdonald DW, Sidorovich VE, Maran T, Kruuk H (2002) European mink, Mustela lutreola: analyses for conservation. Wildlife Conservation Research Unit, Oxford

Maran T (2006) Conservation of the European mink in Estonia: an update 2001-2003. In: Gobierno de la Rioja (ed) Int Conf on the conservation of European mink (Mustela lutreola), Logrono, Proc Book, p 131-142

Maran T, Macdonald DW, Kruuk H, Sidorovich V, Rozhnov VV (1998) The continuing decline of the European mink Mustela lutreola: evidence for the intraguild aggression hypothesis. In: Dunstone N, Gorman M (eds) Behaviour and ecology of riparian mammals. Cambridge University Press, Cambridge, p 297-323

> Maran T, Põdra M, Põlma M, Macdonald DW (2009) The survival of captive-born animals in restoration programmes-case study of the endangered European mink Mustela lutreola. Biol Conserv 142:1685-1692

Maran T, Skumatov D, Palazón S, Gómez A and others (2011) Mustela lutreola. In: IUCN Red List of Threatened Species. IUCN 2013. Version 2013.2. www.iucnredlist. org

> Mathews F, Orros M, McLaren G, Gelling M, Foster R (2005) Keeping fit on the ark: assessing the suitability of captive-bred animals for release. Biol Conserv 121:569-577

> Maxwell JM, Jamieson IG (1997) Survival and recruitment of captive-reared and wild-reared takahe in Fiordland, New Zealand. Conserv Biol 11:683-691

McCarthy MA, Armstrong DP, Runge MC (2012) Adaptive management in reintroduction. In: Ewen JG, Armstrong DP, Parker KA, Seddon PJ (eds) Reintroduction biology. Integrating science and management. Wiley-Blackwell, Chichester, p 256-289

McLean IG, Lundie-Jenkins G, Jarman PJ (1996) Teaching an endangered mammal to recognise predators. Biol Conserv 75:51-62

McLellan SR, Rabon JDR (2006) Translocating red wolves using a modified soft-release technique. Canid News 9.1: $1-10$

McPhee ME (2004) Generations in captivity increases behavioural variance: considerations for captive breeding and reintroduction programs. Biol Conserv 115:71-77

Miller B, Biggins D, Hanebury L, Vargas A (1994) Reintroduction of the black-footed ferret (Mustela nigripes). In: Olney PJS, Mace GM, Feistner ATC (eds) Creative conservation: interactive management of wild and captive animals. Chapman \& Hall, London, p 455-464

> Moehrenschlager A, Macdonald DW (2003) Movement and survival parameters of translocated and resident swift foxes. Anim Conserv 6:199-206

> Moseby KE, Cameron A, Crisp HA (2012) Can predator avoidance training improve reintroduction outcomes for the greater bilby in arid Australia? Anim Behav 83: 1011-1021

Peters E, Brinkmann I, Krüger F, Zwirlein S, Klaumann I (2009) Reintroduction of the European mink Mustela lutreola in Saarland, Germany. Preliminary data on the use of space and activity as revealed by radio-tracking and live-trapping. Endang Species Res 10:305-320

Põdra M, Maran T, Sidorovich VE, Johnson PJ, Macdonald DW (2013a) Restoration programmes and the development of a natural diet: a case study of captive-bred European mink. Eur J Wildl Res 59:93-104 
Põdra M, Gómez A, Palazón S (2013b) Do American milk kill European mink? Cautionary message for future recovery efforts. Eur J Wildl Res 59:431-440

R Development Core Team (2011) R: a language and environment for statistical computing. R Foundation for Statistical Computing, Vienna, Austria. www.r-project.org

Rantanen EM, Buner F, Riordan P, Sotherton N, Macdonald DW (2010a) Habitat preferences and survival in wildlife reintroductions: an ecological trap in reintroduced grey partridges. J Appl Ecol 47:1357-1364

Rantanen EM, Buner F, Riordan P, Sotherton N, Macdonald DW (2010b) Vigilance, time budgets and predation risk in reintroduced captive-bred grey partridges Perdix perdix. Appl Anim Behav Sci 127:43-50

Robertson CPJ, Harris S (1995) The behaviour after release of captive-reared fox cubs. Anim Welf 4:295-306

Roe JH, Frank MR, Gibson SE, Attum O, Kingsbury BA (2010) No place like home: an experimental comparison of reintroduction strategies using snakes. J Appl Ecol 47 : 1253-1261

Seddon PJ, Armstrong DP, Maloney RF (2007) Developing the science of reintroduction biology. Conserv Biol 21: 303-312

Shier DM, Owings DH (2006) Effects of predator training on behavior and post-release survival of captive prairie dogs (Cynomys ludovicianus). Biol Conserv 132:126-135

Sidorovich VE (2011) Analysis of vertebrate predator-prey community. Tesey, Minsk

Sidorovich V, Macdonald DW (2001) Density dynamics and changes in habitat use by the European mink and other native mustelids in connection with the American mink expansion in Belarus. Neth J Zool 51:107-126

Sidorovich V, Kruuk H, Macdonald DW (1999) Body size, and interactions between European and American mink (Mustela lutreola and M. vison) in Eastern Europe. J Zool (Lond) 248:521-527

Editorial responsibility: Nils Bunnefeld, Stirling, UK
Sjöåsen T (1997) Movements and establishment of reintroduced European otters Lutra lutra. J Appl Ecol 34: 1070-1080

Soderquist TR, Serena M (1994) An experimental reintroduction programme for brush-tailed phascogales (Phascogale tapoatafa): the interface between captivity and the wild. In: Olney PJS, Mace GM, Feistner ATC (eds) Creative conservation: interactive management of wild and captive animals. Chapman \& Hall, London, p 431-438

Stamps JA, Swaisgood RR (2007) Someplace like home: experience, habitat selection and conservation biology. Appl Anim Behav Sci 102:392-409

Stoinski TS, Beck BB (2004) Changes in locomotor and foraging skills in captive-born, reintroduced golden lion tamarins (Leontopithecus rosalia rosalia). Am J Primatol 62:1-13

van Heezik Y, Seddon PJ, Maloney RF (1999) Helping reintroduced houbara bustards avoid predation: effective anti-predator training and the predictive value of prerelease behaviour. Anim Conserv 2:155-163

van Heezik Y, Maloney RF, Seddon PJ (2009) Movements of translocated captive-bred and released critically endangered kaki (black stilts) Himantopus novaezelandiae and the value of long-term post-release monitoring. Oryx 43: $639-647$

Zabala J, Zuberogoitia I, Martinez JA (2006) Factors affecting occupancy by the European mink in south-western Europe. Mammalia 3:193-201

Zabala J, Zubergoitia I, Martinez JA (2007) Modelling the incidence of fragmentation at different scales in the European mink (Mustela lutreola) population and the expansion of the American mink (Mustela vison) in Biscay. Small Carnivore Conserv 36:14-17

Zuberogoitia I, Zabala J (2003) Do European mink use only rivers or do they also use other habitats? Small Carnivore Conserv 28:7-8

Submitted: March 6, 2013; Accepted: February 7, 2014

Proofs received from author(s): May 8, 2014 